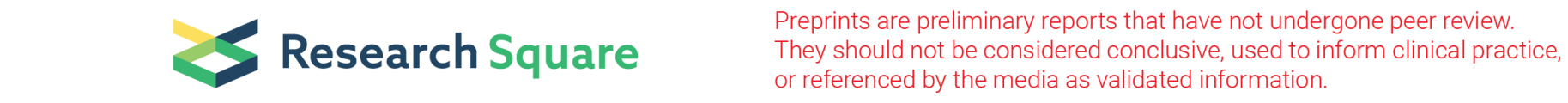

\title{
Glutaric Acidemia type 1 with Atypical Acylcarnitine Profile During Newborn Screening
}

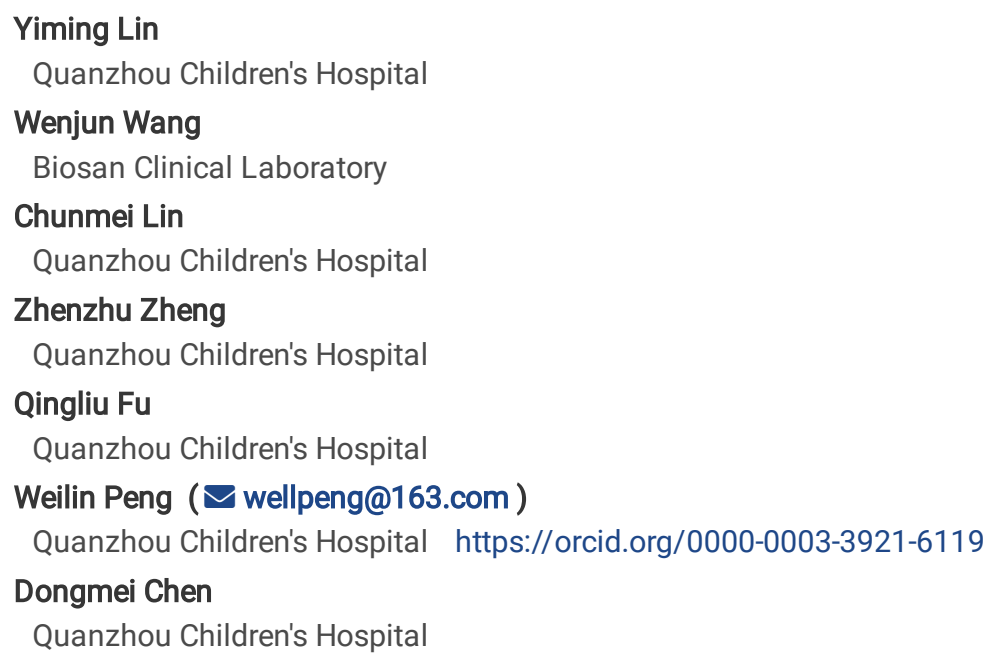

Yiming Lin

Quanzhou Children's Hospital

Wenjun Wang

Biosan Clinical Laboratory

Chunmei Lin

Quanzhou Children's Hospital

Zhenzhu Zheng

Quanzhou Children's Hospital

Qingliu Fu

Quanzhou Children's Hospital

Weilin Peng ( $\square$ wellpeng@163.com)

Quanzhou Children's Hospital https://orcid.org/0000-0003-3921-6119

Dongmei Chen

Quanzhou Children's Hospital

\section{Research Article}

Keywords: Glutaric acidemia type 1, newborn screening, GCDH gene, free carnitine, primary carnitine deficiency

Posted Date: May 5th, 2021

DOI: https://doi.org/10.21203/rs.3.rs-474079/v1

License: (c) (i) This work is licensed under a Creative Commons Attribution 4.0 International License. Read Full License

Version of Record: A version of this preprint was published at Orphanet Journal of Rare Diseases on August 3rd, 2021. See the published version at https://doi.org/10.1186/s13023-021-01964-5. 


\section{Abstract}

\section{Background and aims}

Glutaric acidemia type 1 (GA1) is a treatable disorder of cerebral organic acid metabolism caused by a defective glutaryl-CoA dehydrogenase $(G C D H)$ gene. There is scarcity of reports of GA1 diagnoses following newborn screening (NBS) in the Chinese population. We assessed the acylcarnitine profiles and genetic characteristics of patients with GA1 identified via NBS.

\section{Materials and methods}

From January 2014 to September 2020, a total of 517,484 newborns screened by tandem mass spectrometry were recruited for this study. Newborns with elevated isovalerylcarnitine (C5DC) levels were recalled, those who tested positive on second screen were referred for confirmatory tests.

\section{Results}

Of 517,484 screened newborns, thirteen patients were diagnosed with GA1, including eleven neonatal GA1 and two maternal GA1 patients. The incidence of GA1 in the Quanzhou region was estimated to be 1 in 47,044 newborns. The initial NBS results showed that all but one of the patients had moderately or markedly increased C5DC levels. The neonatal GA1 patient with low free carnitine (C0) level suggestive of primary carnitine deficiency (PCD) while just the contrary to a typical GA1. Nine neonatal GA1 patients underwent urinary organic acid analyses: eight had elevated GA levels and one was reported in the normal range. Ten distinct GCDH variants were identified, eight were previously reported and two were newly identified. In silico prediction tools and protein modelling analysis suggested that the newly identified variants were potentially pathogenic. The most common variant was c.1244-2A > C, which had an allelic frequency of 54.55\% (12/22), followed by c.1261G > A (p.Ala421Thr) $(9.09 \%, 2 / 22)$.

\section{Conclusions}

GA1 patients may show only with low C0 levels at the initial screening and recall stages that may be overlooked. Maternal GA1 patients can also be detected during NBS duo to the low C0 levels in their infants. Therefore, PCD should be included in the differential diagnosis for GA1, and multigene panel testing should be performed in newborns with low CO levels.

\section{Introduction}

Glutaric acidemia type 1 (GA1; OMIM \#231670) is a treatable disorder of cerebral organic acid metabolism caused by a defective glutaryl-CoA dehydrogenase (GCDH) gene, which encodes the glutaryl-CoA dehydrogenase (GCDH, EC 1.3.8.6) that mediates degradation of L-lysine, Lhydroxylysine, and L-tryptophan [1]. This disorder leads to accumulation of glutaric acid (GA) and 3-hydroxyglutaric acid (3HGA) in body tissues, especially in the brain. The clinical presentation of GA1 varies widely and ranges from the more common form (infantile-onset disease: 3 months to 6 years) to less common form (later-onset disease: after age 6 years). Untreated GA1 patients typically present with acute encephalopathy, movement disorders (MD), and striatal damage in the first 3-36 months of life [2]. GA1 was divided into low (LE) and high excretors (HE) based on the amount of urinary GA, however, both biochemical subtypes sharing the same risk of developing MD if left untreated [3-5].

Given that GA1 patients with elevated glutarylcarnitine (C5DC) levels that can be reliably detected by tandem mass spectrometry (MS/MS) and early therapy is effective, GA1 has been included in many national newborn screening (NBS) panels [6, 7]. Previous study has demonstrated that NBS for GA1 has significantly improved the neurologic outcome of affected individuals, early identification through NBS is essential to provide timely treatment and ensure optimal outcomes [8]. However, there is scarcity of data on the incidence, NBS experience, and mutational spectrum in China. We encountered one GA1 patient but with normal C5DC profile at the initial screening. Additionally, two mothers with GA1 were incidentally diagnosed in our NBS program. Herein, we report the acylcarnitine profiles and molecular features of thirteen GA1 patients diagnosed via NBS in a southern Chinese population.

\section{Materials And Methods}

\subsection{Newborn screening and laboratory tests}

From January 2014 to September 2020, a total of 517,484 newborns (292,880 males and 224,604 females) screened via MS/MS in the NBS center at Quanzhou Maternity and Children's Hospital were recruited for this study. Blood samples were collected by heel stick between 3 and 7 days after birth and spotted on Whatman 903 filter paper. Dried blood spot (DBS) samples were delivered by cold-chain transportation to our center within 3 days. DBS samples were pre-processed and then detected using a mass spectrometer, internal and external quality controls were 
performed as previously described [9]. Newborns with elevated C5DC levels were recalled, those who tested positive on second screen were referred for confirmatory tests, including biochemical laboratory tests, urinary organic acid analysis, and genetic analysis. This study was approved by the Ethical Committee of Quanzhou Maternity and Children's Hospital. Written informed consent was obtained from the parents of all patients.

\subsection{Genetic testing and variants analysis}

Targeted next-generation sequencing (NGS) was performed by the Hangzhou Biosan Clinical Laboratory Co. Ltd. (Hangzhou, Zhejiang, China), as previously described [10]. All possible disease-causing variants identified by NGS were further validated by Sanger sequencing of the patients and their parents. The exons of the GCDH gene were amplified by polymerase chain reaction (PCR). Amplified fragments were sequenced directly using an ABI Prism 3500 automatic sequencer (Applied Biosystems, Foster City, CA, USA). The PCR primer sequences and protocols are available upon request. The pathogenicity of novel variants was assessed using several in silico tools, including SIFT, PolyPhen-2, PROVEAN, and MutationTaster. Evolutionary conservation was analyzed using ClustalX (http://www.clustal.org/clustal2). To build threedimensional (3D) models of GCDH, homology modeling was employed using the Swiss Model Workspace with the PDB accession number Q92947, and PDB files were then submitted to Swiss-Pdb Viewer 4.10 for 3D-structure analysis.

\section{Results}

\subsection{NBS for GA1}

A total of 102 newborns had abnormal C5DC concentrations at initial NBS, yielding a positivity rate of 0.02\% (102/517,484). Ten newborns with elevated C5DC levels were diagnosed with GA1, for a positive predictive value (PPV) of 9.8\% (10/102). Surprisingly, one newborn only with low $\mathrm{CO}$ level was also diagnosed with GA1. Hence, the incidence of GA1 in the Quanzhou region was estimated to be 1 in 47,044 newborns. In addition, two mothers were diagnosed with GA1 by the abnormal NBS results of their infants.

\subsection{Biochemical features}

The initial NBS results showed that all but one of the patients had moderately or markedly increased C5DC levels. The patient (no. 7) had normal C5DC level while with extremely low C0 level during NBS. The mean C5DC concentrations during NBS and recall stage in the neonatal GA1 patients were $2.40 \pm 1.08 \mu \mathrm{mol} / \mathrm{L}$ and $2.17 \pm 1.28 \mu \mathrm{mol} / \mathrm{L}$ (reference value: $0.03-0.3 \mu \mathrm{mol} / \mathrm{L}$ ), respectively. Notably, two mothers were found to have GA1 due to the low C0 levels in their infants, both mothers had elevated C5DC levels and low C0 levels. Nine neonatal GA1 patients underwent urinary organic acid analyses: eight had elevated GA levels (HE phenotype) and one was reported in the normal range (LE phenotype) (Table 1). 
Table 1

Biochemical and genetic features of 11 neonatal GA1 patients

\begin{tabular}{|c|c|c|c|c|c|c|c|c|c|c|}
\hline \multirow{2}{*}{$\begin{array}{l}\text { Patient } \\
\text { no. }\end{array}$} & \multirow[t]{2}{*}{ Gender } & \multirow[t]{2}{*}{$\mathrm{Age}^{\mathrm{a}}$} & \multicolumn{2}{|c|}{ Newborn screening } & \multicolumn{2}{|l|}{ Recall } & \multirow{2}{*}{$\begin{array}{l}\text { GA } \\
\text { (mmol/mol } \\
\text { creatinine) }\end{array}$} & \multirow{2}{*}{$\begin{array}{l}\text { Affected } \\
\text { gene }\end{array}$} & \multicolumn{2}{|l|}{ Genotype $^{b}$} \\
\hline & & & $\begin{array}{l}\text { C5DC } \\
(\mu \mathrm{mol} / \mathrm{L})\end{array}$ & $\begin{array}{l}\mathrm{CO} \\
(\mu \mathrm{mol} / \mathrm{L})\end{array}$ & $\begin{array}{l}\text { C5DC } \\
(\mu \mathrm{mol} / \mathrm{L})\end{array}$ & $\begin{array}{l}\mathrm{CO} \\
(\mu \mathrm{mol} / \mathrm{L})\end{array}$ & & & Allele 1 & Allele 2 \\
\hline 1 & $\mathrm{~F}$ & $\begin{array}{l}6 \mathrm{y} \\
5 \mathrm{~m}\end{array}$ & 2.67 & 13.50 & 2.47 & 15.06 & 150.49 & $G C D H$ & $\begin{array}{l}\text { c. } 532 \mathrm{G}>\mathrm{A} \\
\text { (p.Gly178Arg) }\end{array}$ & $\begin{array}{l}\text { c.108_109delAC } \\
\text { (p.Gln37Glufs*5) }\end{array}$ \\
\hline 2 & $\mathrm{~F}$ & $\begin{array}{l}5 y \\
11 \\
m\end{array}$ & 1.45 & 18.32 & 1.50 & 41.12 & 503.79 & $G C D H$ & $\begin{array}{l}\text { c. } 533 \mathrm{G}>\mathrm{A} \\
\text { (p.Gly178Glu) }\end{array}$ & c. $1244-2 A>C$ \\
\hline 3 & $\mathrm{~F}$ & $\begin{array}{l}5 \mathrm{y} \\
9 \mathrm{~m}\end{array}$ & 2.81 & 13.95 & 3.68 & 10.87 & 300.15 & $G C D H$ & c. $1244-2 A>C$ & c. $1244-2 A>C$ \\
\hline 4 & $M$ & $\begin{array}{l}4 \mathrm{y} \\
1 \mathrm{~m}\end{array}$ & 2.42 & 13.06 & N/A & N/A & 409.05 & $G C D H$ & c. $1244-2 A>C$ & c. $1244-2 A>C$ \\
\hline 5 & $\mathrm{~F}$ & $\begin{array}{l}3 \mathrm{y} \\
9 \mathrm{~m}\end{array}$ & 1.90 & 14.25 & 1.92 & 10.20 & 462.83 & $G C D H$ & $\begin{array}{l}\text { c. } 395 \mathrm{G}>\mathrm{A} \\
\text { (p.Arg132GIn) }\end{array}$ & $\begin{array}{l}\text { c. } 1147 \mathrm{C}>\mathrm{T} \\
\text { (p.Arg383Cys) }\end{array}$ \\
\hline 6 & $\mathrm{~F}$ & $\begin{array}{l}3 \mathrm{y} \\
4 \mathrm{~m}\end{array}$ & 3.79 & 13.33 & $\mathrm{~N} / \mathrm{A}$ & N/A & N/A & $G C D H$ & c. $1244-2 A>C$ & $\begin{array}{l}\text { c.1016T > C } \\
\text { (p.Met339Thr) }\end{array}$ \\
\hline 7 & $\mathrm{~F}$ & $\begin{array}{l}3 \mathrm{y} \\
1 \mathrm{~m}\end{array}$ & 0.06 & 3.18 & 0.05 & 7.69 & 1.31 & $G C D H$ & c. $1244-2 A>C$ & $\begin{array}{l}\text { c. } 1261 \mathrm{G}>\mathrm{A} \\
\text { (p.Ala421Thr) }\end{array}$ \\
\hline 8 & $M$ & $\begin{array}{l}2 \mathrm{y} \\
6 \mathrm{~m}\end{array}$ & 1.58 & 16.37 & 2.19 & 29.91 & 313.74 & $G C D H$ & c. $1244-2 A>C$ & c. $1244-2 A>C$ \\
\hline 9 & $M$ & $7 \mathrm{~m}$ & 4.26 & 9.66 & 3.34 & 4.99 & 741.81 & $G C D H$ & c. $1244-2 A>C$ & c. $1244-2 A>C$ \\
\hline 10 & $\mathrm{~F}$ & $6 \mathrm{~m}$ & 2.44 & 10.91 & 3.65 & 9.04 & 434.34 & $G C D H$ & c. $1244-2 A>C$ & $\begin{array}{l}\text { c. } 1261 \mathrm{G}>\mathrm{A} \\
\text { (p.Ala421Thr) }\end{array}$ \\
\hline 11 & $\mathrm{~F}$ & $5 \mathrm{~m}$ & 0.68 & 19.51 & 0.70 & 20.62 & N/A & $G C D H$ & $\begin{array}{l}\text { c.300G >A } \\
\text { (p.Met100lle) }\end{array}$ & $\begin{array}{l}\text { c. } 1204 C>T \\
\text { (p.Arg402Trp) }\end{array}$ \\
\hline
\end{tabular}

Table 2

Biochemical and genetic features of two maternal GA1 patients and their infants

\begin{tabular}{|c|c|c|c|c|c|c|c|c|c|c|}
\hline \multirow[t]{2}{*}{ No. ${ }^{a}$} & \multirow[t]{2}{*}{ Gender } & \multirow[t]{2}{*}{$\mathrm{Age}^{\mathrm{b}}$} & \multicolumn{2}{|c|}{ Newborn screening } & \multicolumn{2}{|l|}{ Recall } & \multirow{2}{*}{$\begin{array}{l}\text { GA } \\
\text { (mmol/mol } \\
\text { creatinine) }\end{array}$} & \multirow{2}{*}{$\begin{array}{l}\text { Affected } \\
\text { gene }\end{array}$} & \multicolumn{2}{|l|}{ Genotype } \\
\hline & & & $\begin{array}{l}\text { C5DC } \\
(\mu \mathrm{mol} / \mathrm{L})\end{array}$ & $\begin{array}{l}\text { CO } \\
(\mu \mathrm{mol} / \mathrm{L})\end{array}$ & $\begin{array}{l}\text { C5DC } \\
(\mu \mathrm{mol} / \mathrm{L})\end{array}$ & $\begin{array}{l}\mathrm{CO} \\
(\mu \mathrm{mol} / \mathrm{L})\end{array}$ & & & Allele 1 & Allele 2 \\
\hline 1 & Female & $\begin{array}{l}37 \mathrm{y} \\
5 \mathrm{~m}\end{array}$ & 1.07 & 4.00 & 1.15 & 5.92 & 579.6 & $G C D H$ & c. $1244-2 A>C$ & c. $1244-2 A>C$ \\
\hline 2 & Male & $\begin{array}{l}4 y \\
10 \\
m\end{array}$ & 0.07 & 4.12 & 0.04 & 5.84 & $\mathrm{~N} / \mathrm{A}$ & $G C D H$ & c. $1244-2 A>C$ & \\
\hline 3 & Female & $\begin{array}{l}34 \mathrm{y} \\
7 \mathrm{~m}\end{array}$ & 0.76 & 2.46 & N/A & N/A & $\mathrm{N} / \mathrm{A}$ & $G C D H$ & $\begin{array}{l}\text { c. } 1063 \mathrm{C}> \\
\text { T(p.Arg355Cys) }\end{array}$ & $\begin{array}{l}\text { c. } 769 \mathrm{C}> \\
\text { T(p.Arg257Trp) }\end{array}$ \\
\hline 4 & Male & $\begin{array}{l}3 \mathrm{y} \\
5 \mathrm{~m}\end{array}$ & 0.06 & 3.68 & 0.03 & 7.16 & $\mathrm{~N} / \mathrm{A}$ & $G C D H$ & $\begin{array}{l}\text { c. } 769 \mathrm{C}> \\
\text { T(p.Arg257Trp) }\end{array}$ & \\
\hline \multicolumn{11}{|c|}{ a: No. 1 and 3 are maternal GA1 patients, No. 2 and 4 are their infants, respectively. } \\
\hline \multicolumn{11}{|c|}{ b: age as of April 2021, m: month, y: year; M: male, F: female. } \\
\hline \multicolumn{11}{|c|}{ C5DC: glutarylcarnitine; C0: free carnitine, GA: glutaric acid, N/A: not available. } \\
\hline \multicolumn{11}{|c|}{ Reference range, C5DC: $0.03-0.3 \mu \mathrm{mol} / \mathrm{L}, \mathrm{C} 0: 8.5-50 \mu \mathrm{mol} / \mathrm{L}, \mathrm{GA}:<2.5 \mathrm{mmol} / \mathrm{mol}$ creatinine. } \\
\hline
\end{tabular}

\subsection{Genetic testing and variants analysis}


All eleven neonatal GA1 patients harbored compound heterozygous or homozygous variants in GCDH. Ten distinct variants were identified, eight of which were previously reported pathogenic variants, and the remaining two variants were newly identified by our team. The most common variant was c.1244-2A > C, which had an allelic frequency of 54.55\% (12/22), followed by c.1261G > A (p.Ala421Thr) (9.09\%, 2/22). Likewise, two maternal GA1 patients had biallelic pathogenic variants in $G C D H$, while their infants were just carriers (Table 1).

The newly identified variants were absent from disease and population databases, in silico analysis suggested that these two variants were potentially pathogenic (Supplementary file 1: Table S1). Alignment of the GCDH sequences revealed that that amino acids at positions 37 and 339 are strictly conserved (Supplementary file 2: Figure S1). The variant c.108_109delAC (p.GIn37Glufs*5) resulting in the premature termination of the protein decreased. According to the UniProt database analysis, the termination of the protein at position 41 affected functional domains of GCDH, including N-terminal (protein position 47-173), Acyl-CoA dehydrogenase, central domain (protein position 176269), and C-terminal (protein position 286-432), which may affect structure and function of protein (Fig. 1). Protein modelling showed that the variant c.1016T > C (p.Met339Thr) increased hydrogen bonds between the protein position 335 and 339, which may affect structure and function of GCDH protein by altering the folding process of protein (Fig. 2).

\section{Discussion}

Since the first description of GA1 patients in 1975, over 600 individuals with GA1 have been documented to date [3]. The birth incidence of GA1 varies between 1:30,000 and 1:100,000 newborns, but much higher prevalence (1:200 to 1:2300) was reported in certain groups such as the Old Order Amish, Irish Travelers, Canadian Ojibway-Cree Indians and black South Africans [11]. The exact incidence of GA1 in China remains unclear, the first multicenter pilot study revealed that the incidence was 1 in 185,971newborns in mainland China [12]. In recent years, an increasing number of GA1 patients were detected during NBS as the accumulation of screening experience and the improvement of genetic diagnosis ability $[13,14]$. The incidence of GA1 in the selected southern Chinese population was about 1 in 47,044 births, which is comparable to other studied populations $[15,16]$. Comparing with the incidence reported in different regions of China, the local incidence is higher that reported in Zhejiang province $(1: 64,708)$ and Jiangsu province $(1: 89,335)$ in southern China $[17,18]$, and Xi'an city $(1: 73,076)$ in northern China [19].

All thirteen GA1 patients in this study were identified through NBS. Interestingly, three patients were found to have GA1 due to the low C0 levels during NBS, rather than typical elevation of C5DC levels, including one neonatal GA1 and two maternal GA1 patients. The neonatal GA1 patient with low C0 level suggestive of primary carnitine deficiency (PCD) while just the contrary to a typical GA1. To our knowledge, this is the first report of neonatal GA1 case with low C0 level diagnosed through NBS. In comparison, both maternal GA1 patients exhibited typical elevated C5DC levels but along with low C0 levels that were significantly different from those of newborns. Therefore, data from this study revealed that PCD should be included in the differential diagnosis for GA1.

Although NBS has a positive effective for GA1 and is a cost-effective diagnostic strategy [20], false-negative results may occurred and several cases missed during NBS due to many factors have been reported [8, 15, 21-23]. The most common factor was that GA1 patients with LE phenotype have normal C5DC levels would escape detection, as evidenced by one of our patients (no. 7) whose C5DC level was far below the upper limit of cutoff value. Unlike the previously reported cases [8, 15, 22, 23], the patient had persistently low C0 levels thus was accidentally detected. The patient would not have been correctly diagnosed if targeted exome sequencing had not been conducted, indicating the importance of performing multigene panel testing in newborns with low $\mathrm{C} 0$ levels. Another factor that led to missed cases was $\mathrm{GA} 1$ patients had an initially elevated C5DC levels but normalized on second screen, which may be caused by secondary carnitine depletion. In addition, improper setting of cutoff values or laboratory interpretation error were responsible for some missed cases.

Adult-onset GA1 is extremely rare. Only few adult cases have been reported so far, and most of which were asymptomatic female patients who were incidentally diagnosed due to the abnormal NBS results of their infants [24-27], This study described two asymptomatic maternal GA1 patients with detail acylcarnitine profiles, which helps to better understand this disorder. The identification of maternal GA1 patients is an additional benefit because these seemingly asymptomatic mothers may develop neurological symptoms, and the preventive metabolic therapy can prevent neurological deterioration.

At least 240 pathogenic GCDH variants have been reported thus far, and several common pan-ethnic pathogenic variants have been identified (http://www.hgmd.cf.ac.uk). In particular, c.1204C > T (p.Arg402Trp) was found to be highly prevalent in several populations, which with a frequency of $12-40 \%$ in western Europe, $57 \%$ in Spain, 50\% in Poland, 18.8\% in India, and 56.38\% in Russia [11, 28]. However, the variant was absent in Japan and was rarely identified in this cohort and previously reported Chinese patients [29-31], indicating ethnic specificity. c. 1244$2 \mathrm{~A}>\mathrm{C}$ was reported as the common variant in southern Chinese origin, while it was not prevalent in other Chinese groups [32-34]. Consistent with previous studies [32, 33], c.1244-2A > C was the most common GCDH variant detected in this cohort of patients, with a high allelic frequency of $54.55 \%$. Thus, the GCDH variant spectra vary significantly between ethnicities, which may also differ among different populations

Page 5/9 
in the same ethnic group. In general, the $G C D H$ variant spectra in this study was quite heterogeneous except for the observed recurrent variant. The newly identified variants in this study expanded the $G C D H$ variant spectra. Combining the in silico prediction tools with protein modelling analysis can further reinforce the reliability of the prediction results.

In summary, this study investigated thirteen Chinese patients with GA1 identified via NBS. The incidence of GA1 in the selected population was estimated to be 1 in 47,044 newborns. The c.1244-2A > C was the most common GCDH variant. The newly identified variants further expanded the GCDH variant spectra. GA1 patients may show only with low $\mathrm{CO}$ levels at the initial screening and recall stages that may be overlooked. Maternal GA1 patients can also be detected during NBS duo to the low $\mathrm{CO}$ levels in their infants. Therefore, PCD should be included in the differential diagnosis for GA1, and multigene panel testing should be performed in newborns with low CO levels.

\section{Abbreviations}

GA1: glutaric acidemia type 1; GA: glutaric acid; 3HGA: 3-hydroxyglutaric acid; MD: movement disorders『LE: low excretor; HE: high excretor; C5DC: glutarylcarnitine; MS/MS: tandem mass spectrometry; NBS: newborn screening; DBS: dried blood spot; NGS: next-generation sequencing; PCR: polymerase chain reaction; 3D: three-dimensional; CO: free carnitine; PCD: primary carnitine deficiency

\section{Declarations}

\section{Ethics approval and consent to participate}

This study was approved by the Ethical Committee of Quanzhou Maternity and Children's Hospital and was performed in accordance with the Declaration of Helsinki. Written informed consent was obtained from the parents of all infants for collection of DBS samples and publication of medical data.

\section{Consent for publication}

Consent was obtained from the parents of all patients for publication.

\section{Availability of data and materials}

The datasets used and/or analysed during the current study can be obtained from the corresponding author upon a reasonable request.

\section{Conflict of Interest}

The authors declare that they have no conflicts of interest.

\section{Author contributions}

YM Lin performed the data analysis, drafted and revised the manuscript; WJ Wang carried out the genetic tests and variants analysis; CM Lin, ZZ Zheng, and QL Fu assisted with data collection; WL Peng assisted with data collection, reviewed and revised the manuscript; DM Chen designed and supervised the research study. All authors contributed to the data analysis, revising and approving the final manuscript to be published.

\section{Research funding}

This work was funded by the Natural Science Foundation of Fujian Province (Grant No. 2020J01130) and the Youth Research Project in the Health System of Fujian Province (Grant No. 2020QNA083).

\section{Acknowledgments}

We thank all the patients and their families for their participation. We would like to thank Editage (www.editage.cn) for English language editing.

\section{References}


1. Couce ML, Lopez-Suarez O, Boveda MD, Castineiras DE, Cocho JA, Garcia-Villoria J et al. Glutaric aciduria type I: outcome of patients with early- versus late-diagnosis. Eur J Paediatr Neurol 2013, 17(4):383-389.

2. Kolker S, Garbade SF, Greenberg CR, Leonard JV, Saudubray JM, Ribes A et al. Natural history, outcome, and treatment efficacy in children and adults with glutaryl-CoA dehydrogenase deficiency. Pediatr Res 2006, 59(6):840-847.

3. Baric I, Wagner L, Feyh P, Liesert M, Buckel W, Hoffmann GF. Sensitivity and specificity of free and total glutaric acid and 3-hydroxyglutaric acid measurements by stable-isotope dilution assays for the diagnosis of glutaric aciduria type I. J Inherit Metab Dis 1999, 22(8):867-881.

4. Christensen E, Ribes A, Merinero B, Zschocke J. Correlation of genotype and phenotype in glutaryl-CoA dehydrogenase deficiency. $J$ Inherit Metab Dis 2004, 27(6):861-868.

5. Boy N, Heringer J, Brackmann R, Bodamer O, Seitz A, Kolker S et al. Extrastriatal changes in patients with late-onset glutaric aciduria type I highlight the risk of long-term neurotoxicity. Orphanet J Rare Dis 2017, 12(1):77.

6. Loeber JG, Burgard P, Cornel MC, Rigter T, Weinreich SS, Rupp K et al. Newborn screening programmes in Europe; arguments and efforts regarding harmonization. Part 1. From blood spot to screening result. $J$ Inherit Metab Dis 2012, 35(4):603-611.

7. Pfeil J, Listl S, Hoffmann GF, Kolker S, Lindner M, Burgard P. Newborn screening by tandem mass spectrometry for glutaric aciduria type 1: a cost-effectiveness analysis. Orphanet J Rare Dis 2013, 8:167.

8. Boy N, Mengler K, Thimm E, Schiergens KA, Marquardt T, Weinhold N et al. Newborn screening: A disease-changing intervention for glutaric aciduria type 1. Ann Neurol 2018, 83(5):970-979.

9. Lin Y, Chen D, Peng W, Wang K, Lin W, Zhuang J et al. Newborn screening for isovaleric acidemia in Quanzhou, China. Clin Chim Acta 2020, 509:25-29.

10. Lin Y, Gao H, Lin C, Chen Y, Zhou S, Lin W et al. Biochemical, Clinical, and Genetic Characteristics of Short/Branched Chain Acyl-CoA Dehydrogenase Deficiency in Chinese Patients by Newborn Screening. Front Genet 2019, 10:802.

11. Boy N, Muhlhausen C, Maier EM, Heringer J, Assmann B, Burgard P et al. Proposed recommendations for diagnosing and managing individuals with glutaric aciduria type I: second revision. J Inherit Metab Dis 2017, 40(1):75-101.

12. Shi XT, Cai J, Wang YY, Tu WJ, Wang WP, Gong LM et al. Newborn screening for inborn errors of metabolism in mainland china: 30 years of experience. JIMD Rep 2012, 6:79-83.

13. Lin Y, Zheng Q, Zheng T, Zheng Z, Lin W, Fu Q. Expanded newborn screening for inherited metabolic disorders and genetic characteristics in a southern Chinese population. Clin Chim Acta 2019, 494:106-111.

14. Wang T, Ma J, Zhang Q, Gao A, Wang Q, Li H et al. Expanded Newborn Screening for Inborn Errors of Metabolism by Tandem Mass Spectrometry in Suzhou, China: Disease Spectrum, Prevalence, Genetic Characteristics in a Chinese Population. Front Genet 2019, $10: 1052$.

15. Couce ML, Castineiras DE, Boveda MD, Bana A, Cocho JA, Iglesias AJ et al. Evaluation and long-term follow-up of infants with inborn errors of metabolism identified in an expanded screening programme. Mol Genet Metab 2011, 104(4):470-475.

16. Viau K, Ernst SL, Vanzo RJ, Botto LD, Pasquali M, Longo N. Glutaric acidemia type 1: outcomes before and after expanded newborn screening. Mol Genet Metab 2012, 106(4):430-438.

17. Yang L, Yin H, Yang R, Huang X. Diagnosis, treatment and outcome of glutaric aciduria type I in Zhejiang Province, China. Med Sci Monit 2011, 17(7):PH55-59.

18. Yang Y, Wang L, Wang B, Liu S, Yu B, Wang T. Application of Next-Generation Sequencing Following Tandem Mass Spectrometry to Expand Newborn Screening for Inborn Errors of Metabolism: A Multicenter Study. Front Genet 2019, 10:86.

19. Zhang R, Qiang R, Song C, Ma X, Zhang Y, Li F et al. Spectrum analysis of inborn errors of metabolism for expanded newborn screening in a northwestern Chinese population. Sci Rep 2021, 11(1):2699.

20. Boy N, Mengler K, Heringer-Seifert J, Hoffmann GF, Garbade SF, Kolker S. Impact of newborn screening and quality of therapy on the neurological outcome in glutaric aciduria type 1: a meta-analysis. Genet Med 2021, 23(1):13-21.

21. Estrella J, Wilcken B, Carpenter K, Bhattacharya K, Tchan M, Wiley V. Expanded newborn screening in New South Wales: missed cases. J Inherit Metab Dis 2014, 37(6):881-887.

22. Wilcken B, Wiley V, Hammond J, Carpenter K. Screening newborns for inborn errors of metabolism by tandem mass spectrometry. N Engl J Med 2003, 348(23):2304-2312.

23. Frazier DM, Millington DS, McCandless SE, Koeberl DD, Weavil SD, Chaing SH et al. The tandem mass spectrometry newborn screening experience in North Carolina: 1997-2005. J Inherit Metab Dis 2006, 29(1):76-85.

24. Mc HJ, Laj K, S BW. Screening of a healthy newborn identifies three adult family members with symptomatic glutaric aciduria type I. $B B A$ Clin 2014, 1:30-32.

25. Gelener P, Severino M, Diker S, Terali K, Tuncel G, Tuzlali H et al. Adult-onset glutaric aciduria type I: rare presentation of a treatable disorder. Neurogenetics 2020, 21(3):179-186. 
26. Stepien KM, Pastores GM, Hendroff U, McCormick C, Fitzimons P, Khawaja N et al. Two Uneventful Pregnancies in a Woman with Glutaric Aciduria Type 1. JIMD Rep 2018, 41:29-36.

27. Garcia P, Martins E, Diogo L, Rocha H, Marcao A, Gaspar E et al. Outcome of three cases of untreated maternal glutaric aciduria type I. Eur J Pediatr 2008, 167(5):569-573.

28. Kurkina MV, Mihaylova SV, Baydakova GV, Saifullina EV, Korostelev SA, Pyankov DV et al. Molecular and biochemical study of glutaric aciduria type 1 in 49 Russian families: nine novel mutations in the GCDH gene. Metab Brain Dis 2020, 35(6):1009-1016.

29. Mushimoto Y, Fukuda S, Hasegawa Y, Kobayashi H, Purevsuren J, Li H et al. Clinical and molecular investigation of 19 Japanese cases of glutaric acidemia type 1. Mol Genet Metab 2011, 102(3):343-348.

30. Wang Q, Li X, Ding Y, Liu Y, Song J, Yang Y. Clinical and mutational spectra of 23 Chinese patients with glutaric aciduria type 1. Brain Dev 2014, 36(9):813-822.

31. Xiao B, Qiu W, Ye J, Zhang H, Zhu H, Wang L et al. Prenatal Diagnosis of Glutaric Acidemia I Based on Amniotic Fluid Samples in 42 Families Using Genetic and Biochemical Approaches. Front Genet 2020, 11:496.

32. Lee CS, Chien YH, Peng SF, Cheng PW, Chang LM, Huang AC et al. Promising outcomes in glutaric aciduria type I patients detected by newborn screening. Metab Brain Dis 2013, 28(1):61-67.

33. Hsieh CT, Hwu WL, Huang YT, Huang AC, Wang SF, Hu MH et al. Early detection of glutaric aciduria type I by newborn screening in Taiwan. J Formos Med Assoc 2008, 107(2):139-144.

34. Zhang Y, Li H, Ma R, Mei L, Wei X, Liang D et al. Clinical and molecular investigation in Chinese patients with glutaric aciduria type I. Clin Chim Acta 2016, 453:75-79.

\section{Figures}

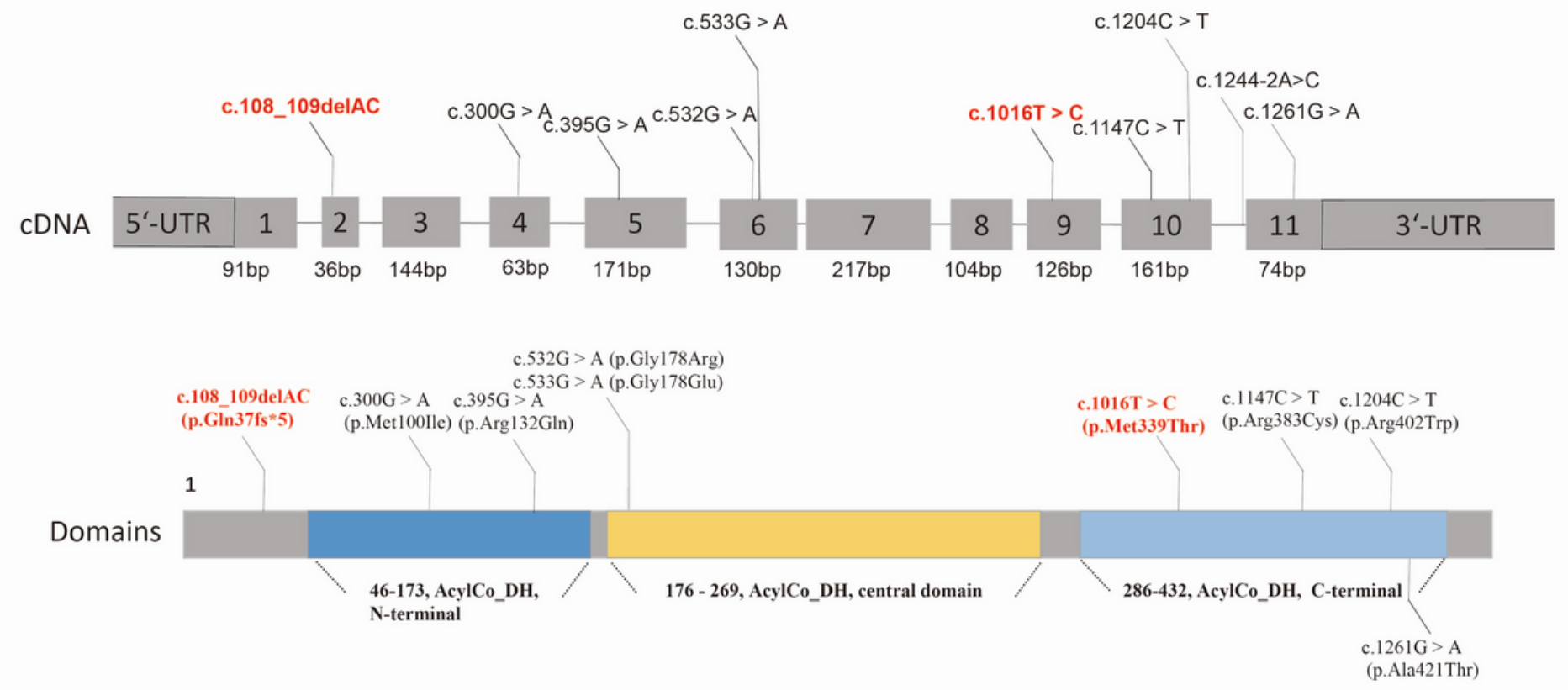

\section{Figure 1}

GCDH variant spectra and Glutaryl-CoA dehydrogenase domains (The newly identified variants by our team were highlighted in red; AcylCo_DH represent Acyl-CoA dehydrogenase). 


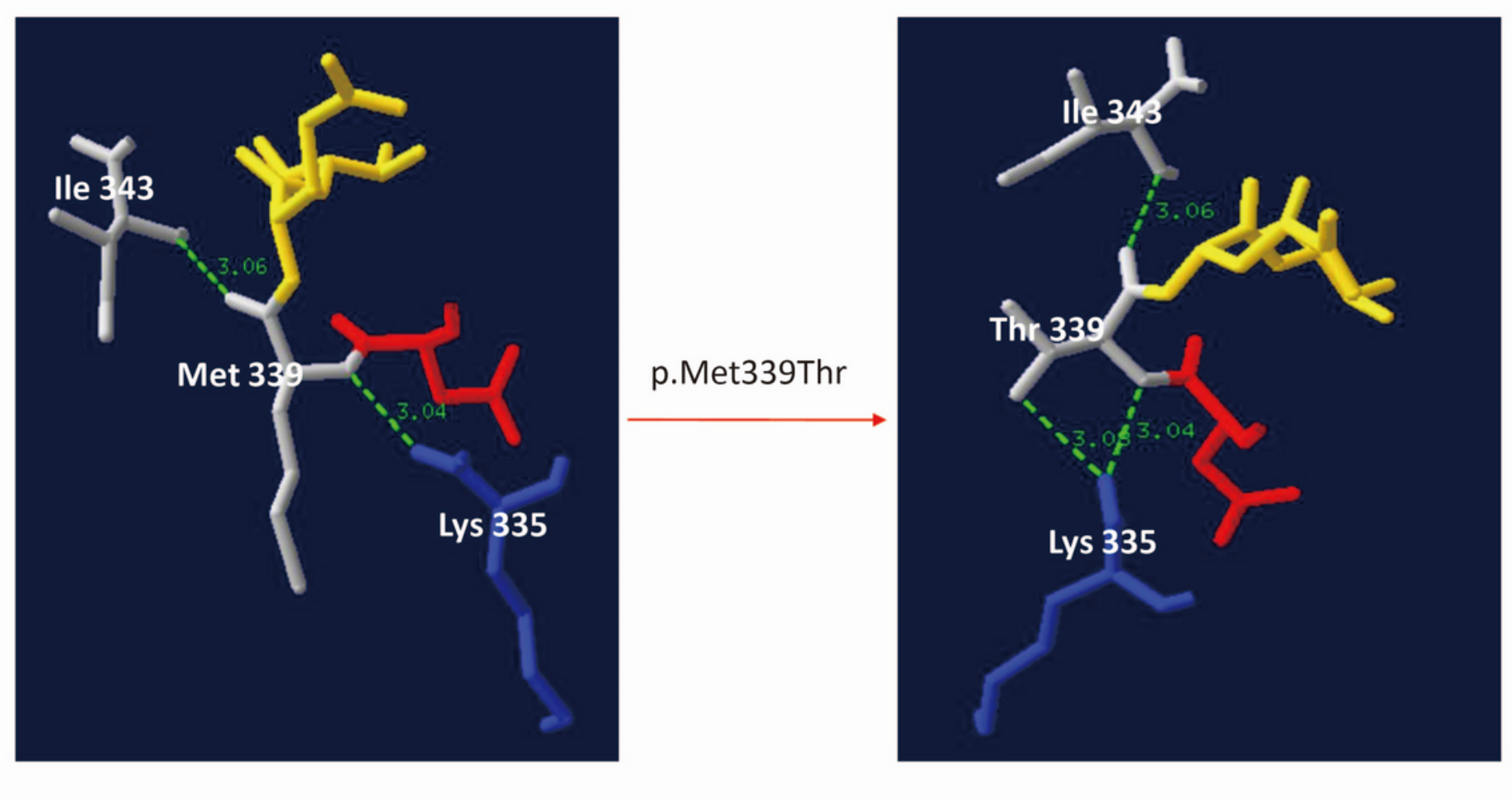

Figure 2

Three-dimensional modeling structure analysis of wild-type and mutant products of GCDH. Green dashed lines represent hydrogen bonds and the green number shows the hydrogen bonds distances. Protein modelling showed that the variant c.1016T > C (p.Met339Thr) increased hydrogen bonds between the protein position 335 and 339, which may affect structure and function of GCDH protein by altering the folding process of protein.

\section{Supplementary Files}

This is a list of supplementary files associated with this preprint. Click to download.

- Supplementaryfile1.TableS1.docx

- Supplementaryfile2.FigureS1.tiff 